\title{
Successful Use of Ketamine for Burst Suppression in Super Refractory Status Epilepticus Following Substance Abuse
}

\author{
Dnyaneshwar P. Mutkule, S. Manimala Rao, Jaydip Ray Chaudhuri', Kunche Rajasri \\ Departments of Critical Care Medicine and 'Neurology, Yashoda Hospital, Hyderabad, Telangana, India
}

\section{Abstract}

Status epilepticus is frequently encountered in neuro Intensive Care Units. It is a medical emergency and if not treated promptly can lead to severe brain damage and even death. Here, we present the case of a 18-year-old male with uncontrolled and unrelenting seizures with a rare etiology requiring ketamine infusion for burst suppression as it was resistant to thiopentone and midazolam infusions. The management of this case is presented in detail.

Keywords: Burst suppression, ketamine, status epilepticus

\section{INTRODUCTION}

It is not uncommon to treat seizures in Intensive Care Units (ICUs) due to various causes and also status epilepticus (SE) with burst suppression. Seizures persisting or recurring after adequate doses of benzodiazepine followed by a second acceptable anti-epileptic drug (AED) are considered to be refractory. When the bolus intermittent therapy of AED fails, continuous infusion of anesthetic agents is recommended. ${ }^{[1]}$ Super refractory status epilepticus (SRSE) is defined as SE that continues or recurs $24 \mathrm{~h}$ or more after the onset of anesthetic therapy, including those cases where SE recurs on reduction or withdrawal of anesthesia. ${ }^{[2]}$ Around $10 \%-15 \%$ of patients admitted to hospital become super refractory. The reported mortality is $35 \%$ and the incidence of severe neurological deficit in such cases is $13 \%{ }^{[3]}$ The common causes are very well documented in the literature along with uncommon causes such as drug intoxications [Table 1]. ${ }^{[4]}$ We present a rare case of SRSE following marijuana intoxication requiring burst suppression with ketamine infusion for almost 7 days. The gold standard for achieving burst suppression in SE is thiopentone and midazolam which were found inefficient requiring ketamine for the same.

\section{Case Report}

An 18-year-old college student came with intractable seizures, received midazolam and levetiracetam, and then shifted to

\begin{tabular}{|l|l|}
\hline \multicolumn{3}{c|}{ Access this article online } \\
\hline Quick Response Code: & Website: \\
& www.ijccm.org \\
\hline
\end{tabular}

ICU after a computed tomography (CT) brain. In the ICU, lumbar puncture was performed immediately for cerebrospinal fluid (CSF) analyses as the CT scan of brain was normal and there was a history of febrile illness of 4 days. The patient was intubated and ventilated on the same day for repeated seizures which continued to occur in spite of higher doses of multiple antiepileptic agents such as midazolam, levetiracetam, lacosamide, and later phenytoin, clobazam, and valproate. Even though phenobarbitone and topiramate were also tried later as the intermittent seizure, vertical nystagmus and epileptiform discharges on electroencephalogram did not disappear. Hence, on day 3 of admission, thiopentone $4 \mathrm{mg} / \mathrm{kg}$ intravenous (IV) bolus followed by up to $4 \mathrm{mg} / \mathrm{kg} / \mathrm{h}$ infusion was added with midazolam infusion to achieve burst suppression. But when this was ineffective, the burst suppression was finally achieved with IV ketamine $1 \mathrm{mg} / \mathrm{kg}$ bolus followed by $2 \mathrm{mg} / \mathrm{kg} / \mathrm{h}$ infusion which was continued for $48 \mathrm{~h}$ and then tapered off slowly over the next 5 days. As the parents of the patient did not reveal history of substance abuse initially, he was extensively investigated. Meanwhile, all the investigations

Address for correspondence: Dr. S. Manimala Rao,
Department of Critical Care Medicine, Yashoda Hospital, Somajiguda,
Hyderabad - 500 082, Telangana, India.
E-mail: manimalara0@hotmail.com




\begin{tabular}{|c|c|c|}
\hline S No. & Etiology & Percentage \\
\hline 1 & Infection & 19 \\
\hline 2 & Preexisting epilepsy & 18 \\
\hline 3 & Metabolic & 13 \\
\hline 4 & Acute stroke & 11 \\
\hline 5 & Tumor related & 10 \\
\hline 6 & Alcohol or another drug withdrawal & 9 \\
\hline 7 & Drug intoxication & 6 \\
\hline 8 & Acute hypoxemic ischemic encephalopathy & 6 \\
\hline 9 & Acute trauma & 6 \\
\hline 10 & Miscellaneous or undetermined & 2 \\
\hline
\end{tabular}

such as CSF for viral, bacterial, and fungal infections, magnetic resonance imaging with contrast, blood cultures, and serology for any common and rare bacterial, tropical, viral, or parasitic infections along with antinuclear antibodies profile, and autoimmune encephalitis panel were followed. But when all the test results were negative, the patient's brother revealed that the patient was habituated to smoking weed (synthetic marijuana). As it was the $5^{\text {th }}$ day of admission, the urine toxicology report was also negative for marijuana. But when we searched the literature, we found that the synthetic marijuana is available in different forms and its ingredients are too toxic and can cause refractory status epilepticus (RSE) as in this case. He developed ventilator-associated pneumonia on the $8^{\text {th }}$ day of ICU stay which was treated with meropenem and colistin and then he was tracheostomized on the $10^{\text {th }}$ day and subsequently weaned off ventilator over a period of another 7 days as all the sedatives and most of the antiepileptics were tapered off. Then, he was decannulated on the $20^{\text {th }}$ day and shifted out of the ICU the next day. The patient was discharged on the $25^{\text {th }}$ day without any sensory motor deficit to follow-up after 7 days.

\section{Discussion}

$\mathrm{SE}$ is an acute and severe illness of the central nervous system and prolonged SE can lead to brain damage and even death. Ketamine is a noncompetitive antagonist of glutamatergic N-methyl-D-aspartate (NMDA) receptors. During prolonged seizures, the number and activity of the gamma-aminobutyric acid receptors gradually decrease, making it resistant to the first- and second-line AEDs. Simultaneously, the numbers and activity of the glutamatergic NMDA receptors increase often causing RSE, providing the rationale for using ketamine. ${ }^{[5]}$ Studies have demonstrated the efficacy and safety of ketamine for the treatment of RSE. ${ }^{[6,7]} \mathrm{RSE}$ carries a mortality rate as high as $23 \%-61 \%$ depending on the underlying cause and the time taken to start the treatment. ${ }^{[1]}$ Although drug intoxication accounts for about $6 \%$ of all the causes of RSE, marijuana is a rare cause. According to a recent review, synthetic marijuana compounds (K2/spice) are falsely marketed to adolescents as a safe alternative to marijuana and are widely known to avoid detection in standard drug screens as they lack structural similarity to tetrahydrocannabinol, the active ingredient in marijuana ${ }^{[8]}$ The exact mechanism of toxicity is unknown, but it is stated that these synthetic cannabinoids act through $\mathrm{CB} 1$ and $\mathrm{CB} 2$ cannabinoid receptors which are present all over the brain and are linked to a number of serious side effects, including seizures, psychosis, and even death, although it has been suggested that cannabidiol might reduce seizure and might have an adequate safety profile in children and young adults with highly treatment-resistant epilepsy. ${ }^{[9]}$ This case reiterates the usefulness of ketamine for SRSE and emphasizes on detailed and repeated history taking with a high index of suspicion about substance abuse.

\section{Declaration of patient consent}

The authors certify that they have obtained all appropriate patient consent forms. In the form, the patient has given his consent for his images and other clinical information to be reported in the journal. The patient understand that his name and initials will not be published and due efforts will be made to conceal identity, but anonymity cannot be guaranteed.

\section{Acknowledgments}

We gratefully acknowledge the ICU doctors, nurses, and management of the hospital for their valuable support.

\section{Financial support and sponsorship}

Nil.

\section{Conflicts of interest}

There are no conflicts of interest.

\section{References}

1. Brophy GM, Bell R, Claassen J, Alldredge B, Bleck TP, Glauser T, et al. Guidelines for the evaluation and management of status epilepticus. Neurocrit Care 2012;17:3-23.

2. Shorvon S, Ferlisi M. The treatment of super-refractory status epilepticus: A critical review of available therapies and a clinical treatment protocol. Brain 2011;134:2802-18.

3. Shrestha GS, Joshi P, Chhetri S, Karn R, Acharya SP. Intravenous ketamine for treatment of super-refractory convulsive status epilepticus with septic shock: A report of two cases. Indian J Crit Care Med 2015;19:283-5.

4. Bleck TP. Less common etiologies of status epilepticus. Epilepsy Curr 2010;10:31-3.

5. Fang Y, Wang X. Ketamine for the treatment of refractory status epilepticus. Seizure 2015;30:14-20.

6. Gaspard N, Foreman B, Judd LM, Brenton JN, Nathan BR, McCoy BM, et al. Intravenous ketamine for the treatment of refractory status epilepticus: A retrospective multicenter study. Epilepsia 2013;54:1498-503.

7. Synowiec AS, Singh DS, Yenugadhati V, Valeriano JP, Schramke CJ, Kelly KM, et al. Ketamine use in the treatment of refractory status epilepticus. Epilepsy Res 2013;105:183-8.

8. Ford BM, Tai S, Fantegrossi WE, Prather PL. Synthetic pot: Not your grandfather's marijuana. Trends Pharmacol Sci 2017;38:257-76.

9. Devinsky O, Marsh E, Friedman D, Thiele E, Laux L, Sullivan J, et al. Cannabidiol in patients with treatment-resistant epilepsy: An open-label interventional trial. Lancet Neurol 2016;15:270-8. 